\title{
Speed Control of a Squirrel Cage Induction Motor with A balanced Capacitor Voltage Fed Multi-Level Diode Clamped Converter
}

\author{
Crescent Onyebuchi Omeje ${ }^{1,}$ \\ ${ }^{1}$ Electrical/Electronic Engineering, \\ University of Port Harcourt, Rivers State Nigeria
}

\author{
Marcel Ugwuoke $\mathrm{Agu}^{2}$ \\ ${ }^{2}$ Electrical Engineering, \\ University of Nigeria Nsukka, Enugu State Nigeria
}

\begin{abstract}
This paper analyzes the concepts of a well-balanced capacitor voltage fed multi-level diode clamped converter driving a three phase squirrel cage induction motor at a varying load. The speed operations in motoring and in generating modes are considered. Speed control of the asynchronous machine is analyzed with pertinent to variable voltage and frequency (V/F) ratio at a low frequency boostvoltage. The effect of load variation on the motor speed in modified closed loop drive system with a low-frequency boost voltage is also examined in this paper. A comparison of the results obtained for the two modes of operation is presented. The simulation results indicate that a closed loop control system proffers a better and an efficient speed control at variable voltage and slip-frequency when operated with a multi-level diode clamped converter at a modulation index of 0.8. It is also shown that the induction machine runs at a very high speed above the synchronous speed value under a generating mode of operation. All simulation processes were achieved in MATLAB 7.14.
\end{abstract}

Keyword: Capacitor Voltage Balancing, Multi-Level Diode Clamped Converter, Squirrel Cage Induction Motor, Constant $V / F$, Motor Speed and Torque.

\section{INTRODUCTION}

Speed control of an induction machine is a very significant aspect in most industrial applications since induction motor is used in number of applications such as steel mills, pump operation, cranes, hoist drives, conveyors and traction systems [1,2,3]. Generally, the speed of a squirrel cage induction machine can be controlled to operate either in a motoring state or in a generating state [4-5]. Conventionally, variable voltage and variable frequency methods have been applied in the speed control of induction machine [6-7]. In automobile applications, speed control is the most crucial aspect of effective machines operation. This is achieved through the following methods: (i) Pole changing of the machine, (ii) Supply Frequency Control, (iii) Stator Voltage Control and (iv) Rotor Resistance Control [8, 9, 10]. The frequency and voltage control methods can be analyzed in scalar and in vector form [11]. In this paper, analysis is based on scalar control. This involves a low-frequency stator boost voltage control with a well-balanced capacitor voltage fed five-level diode clamped converter. This converter drives the squirrel cage induction machine in a closed loop system under a varying machine load and speed. The speed variation which is as a consequence of change in mechanical load is considered in motoring and in generating states. These operational states are compared with respect to the motor speed. A high speed with magnitude above the synchronous speed value is achieved at the generating state whereas a lower speed magnitude below the synchronous speed is achieved at the motoring state.

\section{ANALYSIS OF LOW FREQUENCY STATOR VOLTAGE BOOST.}

The modified voltage-frequency control $\left(\frac{V}{F}\right)$ provides a boost-voltage at low frequencies below the rated value. This boost-voltage compensates for the stator impedance drop that allows a constant flux operation and maximum motoring torque from zero to rated speed [12]. The exact equivalent circuit shown in Figure $1 \mathrm{a}$ is applied in determining the low frequency boost voltage $V_{0}$ that sustains the motor flux from zero to rated speed.

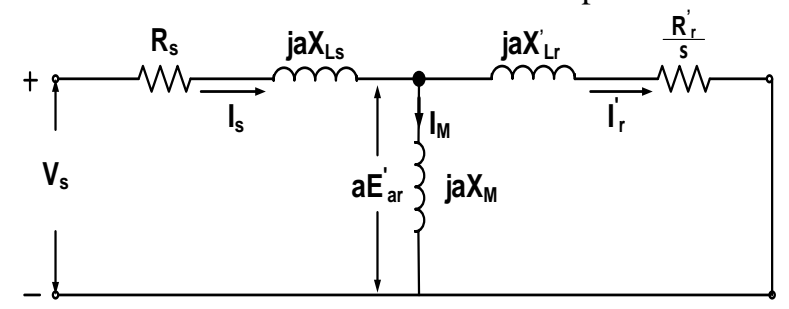

Figure 1a. Steady State Equivalent Circuit of a Squirrel Cage Induction Motor for Variable V/ F control.

The ratio of the operating speed to the rated speed which is also a function of the frequency ratio is given by (1).

$$
\mathrm{a}=\frac{\mathrm{F}_{\text {operating frequency }}}{\mathrm{F}_{\text {rated frequency }}}=\frac{\omega_{\mathrm{s}}}{\omega_{\mathrm{sr}}}
$$

Applying Kirchhoff's Voltage Law in Figure 1a gives rise to $(2)$.

$$
\mathrm{V}_{\mathrm{s}}=\mathrm{aE}_{\mathrm{ar}}+\left(\mathrm{I}_{\mathrm{m}}+\mathrm{I}_{\mathrm{r}}^{\prime}\right) \times\left(\mathrm{R}_{\mathrm{s}}+\mathrm{jaX}_{\mathrm{Ls}}\right)
$$

Where:

$$
I_{m}+I_{r}^{\prime}=\frac{E_{a r}}{j X_{m}}+\frac{a E_{a r}}{\frac{R_{r}^{\prime}}{s}+j a X_{L r}^{\prime}}
$$

Substituting (3) into (2) gives rise to (4).

$$
\mathrm{V}_{\mathrm{S}}=\mathrm{aE}_{\mathrm{ar}}+\left(\frac{\mathrm{E}_{\mathrm{ar}}}{\mathrm{j} \mathrm{X}_{\mathrm{m}}}+\frac{\mathrm{aE} \mathrm{Er}_{\mathrm{r}}}{\frac{\mathrm{R}_{\mathrm{r}}^{\prime}}{\mathrm{s}}+\mathrm{jaX}_{\mathrm{Lr}}^{\prime}}\right)\left(\mathrm{R}_{\mathrm{s}}+\mathrm{jaX}_{\mathrm{Ls}}\right)
$$

At a low frequency of $0.1 \leq a \leq 1$, a plot of the terminal voltage Vs within this range of ' $a$ ' is presented in Figure 1b. The linear graph in Figure $1 \mathrm{~b}$ can be represented in a linear form as shown in (5). 


$$
\mathrm{V}_{\mathrm{s}}=\mathrm{V}_{0}+\mathrm{Ka}
$$

Where $V_{s}$ is the low frequency stator boost voltage. $V_{0}$ is the offset voltage or stator voltage which is chosen to give the rated magnetizing current at zero speed when $\mathrm{a}=0$. By extrapolation $V_{0}=13.33 \mathrm{~V}$ which represents the low frequency stator boost voltage. The slope of the linear graph is given by $K=218.35$. Substituting the value of $K$ and $\mathrm{V}_{0}$ into (5) gives rise to (6).

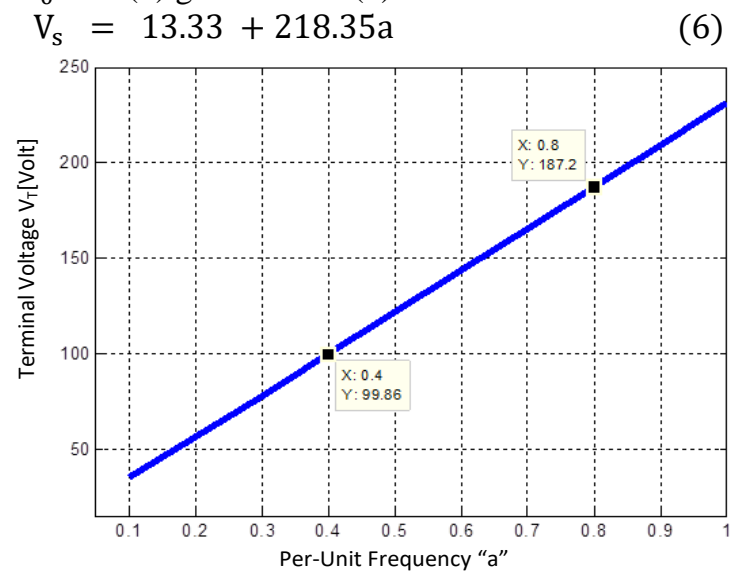

Figure 1b. Stator Terminal Voltage Variation against per unit frequency ratio (a).

The expression in (6) formed the basic equation for the low frequency stator boost voltage which was applied in the closed loop speed control of the squirrel cage induction machine shown in Figure 2.

\section{CLOSED LOOP SPEED CONTROL OF SQUIRREL CAGE INDUCTION MOTOR.}

A closed loop speed control can be implemented with the variable voltage and frequency method through a slip speed regulation. A proportional integral controller is applied to regulate the slip speed of the motor to a set value. The major blocks that make up the components of the electric drives for the speed control as presented in Figure 2 include: (i) The d.c source of supply (ii) The power semiconductor converter (iii) The induction motor and (iv) The controllers. Frequency control is achieved through the speed feedback loop which generates a slip speed $\omega_{S L}=$ $\omega_{m}^{*}-\omega_{m}$. The slip speed difference is acted upon by a PI-controller to reduce the error in speed. A slip limiter set at $\pm 0.7 \mathrm{~S}_{\max }$ is applied to regulate the slip speed of the motor to a permissible value. The resultant speed is summed with a mechanical speed from the rotor sensed through a tachometer to produce a slip frequency. The slip frequency is then supplied to the pulse-width modulator of the five-level diode clamped converter shown in Figure 2. Voltage Control is achieved by summing the values of the adjusted low frequency stator boost voltage in (6) with the actual stator supply voltage obtained from the five-level diode clamped converter. The voltage error produced is regulated with a PI-controller to produce the desired voltage applied in the pulse width modulator of the fivelevel diode clamped converter. This process continues until the machine is shut-down. The various advantages of variable voltage and frequency control include but not limited to the followings: (i) Motor acceleration is easily controlled by controlling the rate of change in supply frequency (ii) A wider stable speed operating region is achieved (iii) A good running and transient performance is easily obtained (iv) Voltage and frequency can easily attain rated values at base speed.

In the closed loop analysis of squirrel cage induction motor, the dynamic equations are essential in the prediction of transient characteristics of the machine speed. The following assumptions as reported in [13-14] are made in the development of transient equations for the conventional squirrel cage induction machine model:

(i) Machine stator voltages are balanced with a sinusoidally distributed magneto-motive force (mmf)

(ii) Saturation effect of the magnetizing core is neglected

(iii) Harmonic contents of the magneto-motive force (mmf) wave are neglected.

(iv) The machine is symmetrical with a linear air-gap and magnetic circuit

The differential equations that describe the dynamic performance of an ideal symmetrical induction machine in a stationary reference frame is presented in (7).

$\left[\begin{array}{c}\mathrm{V}_{\mathrm{qs}} \\ \mathrm{V}_{\mathrm{ds}} \\ 0 \\ 0\end{array}\right]$

$=\left[\begin{array}{cccc}\left(\mathrm{R}_{\mathrm{s}}+\mathrm{L}_{\mathrm{s}} p\right) & 0 & \mathrm{~L}_{\mathrm{m}} p & 0 \\ 0 & \left(\mathrm{R}_{\mathrm{s}}+\mathrm{L}_{\mathrm{s}} p\right) & 0 & \mathrm{~L}_{\mathrm{m}} p \\ \mathrm{~L}_{\mathrm{m}} p & -\omega_{\mathrm{r}} \mathrm{L}_{\mathrm{m}} & \left(\mathrm{R}_{\mathrm{r}}+\mathrm{L}_{\mathrm{r}} p\right) & -\omega_{\mathrm{r}} \mathrm{L}_{\mathrm{r}} \\ \omega_{\mathrm{r}} \mathrm{L}_{\mathrm{m}} & \mathrm{L}_{\mathrm{m}} p & \omega_{\mathrm{r}} \mathrm{L}_{\mathrm{r}} & \left(\mathrm{R}_{\mathrm{r}}+\mathrm{L}_{\mathrm{r}} p\right)\end{array}\right]$

$\times\left[\begin{array}{c}i_{\mathrm{qs}} \\ \mathrm{i}_{\mathrm{ds}} \\ \mathrm{i}_{\mathrm{qr}} \\ i_{\mathrm{dr}}\end{array}\right]$

Where: $\mathrm{L}_{\mathrm{s}}=\mathrm{L}_{\mathrm{Ls}}+\mathrm{L}_{\mathrm{m}}$

$$
\mathrm{L}_{\mathrm{r}}=\mathrm{L}_{\mathrm{Lr}}+\mathrm{L}_{\mathrm{m}}
$$

For simulation purposes, (7) can be compressed and represented by (10).

Where:

$$
p[\mathrm{i}]=-[\mathrm{L}]^{-1}\left([\mathrm{R}]+\omega_{\mathrm{r}}[\mathrm{G}]\right)[\mathrm{i}]+[\mathrm{L}]^{-1}[\mathrm{~V}]
$$

$$
\begin{gathered}
{[\mathrm{V}]=\left[\begin{array}{llll}
\mathrm{V}_{\mathrm{qs}} & \mathrm{V}_{\mathrm{ds}} & 0 & 0
\end{array}\right]^{\prime}} \\
{[\mathrm{R}]=\left[\begin{array}{cccc}
\mathrm{R}_{\mathrm{s}} & 0 & 0 & 0 \\
0 & \mathrm{R}_{\mathrm{s}} & 0 & 0 \\
0 & 0 & \mathrm{R}_{\mathrm{r}} & 0 \\
0 & 0 & 0 & \mathrm{R}_{\mathrm{r}}
\end{array}\right]} \\
{[\mathrm{L}]=\left[\begin{array}{cccc}
\mathrm{L}_{\mathrm{s}} & 0 & \mathrm{~L}_{\mathrm{m}} & 0 \\
0 & \mathrm{~L}_{\mathrm{s}} & 0 & \mathrm{~L}_{\mathrm{m}} \\
\mathrm{L}_{\mathrm{m}} & 0 & \mathrm{~L}_{\mathrm{r}} & 0 \\
0 & \mathrm{~L}_{\mathrm{m}} & 0 & \mathrm{~L}_{\mathrm{r}}
\end{array}\right]} \\
{[\mathrm{G}]=\left[\begin{array}{cccc}
0 & 0 & 0 & 0 \\
0 & 0 & 0 & 0 \\
0 & -\mathrm{L}_{\mathrm{m}} & 0 & -\mathrm{L}_{\mathrm{r}} \\
\mathrm{i}]=\left[\mathrm{i}_{\mathrm{qs}}\right. & 0 & \mathrm{~L}_{\mathrm{r}} & 0
\end{array}\right]}
\end{gathered}
$$




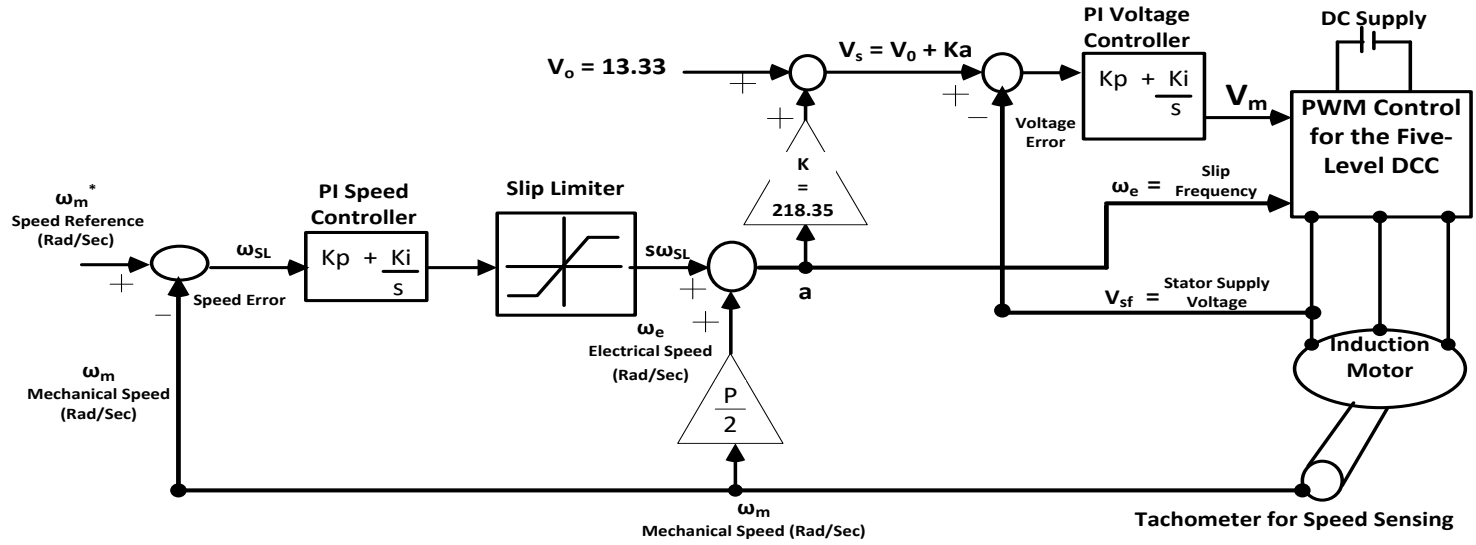

Figure 2 Block diagram of the closed loop speed control of squirrel cage induction motor with V/F scheme.

Where: $p=\frac{\mathrm{d}}{\mathrm{dt}}, \mathrm{R}_{\mathrm{s}}$ is the stator resistance, $\mathrm{R}_{\mathrm{r}}$ is the rotor resistance referred to the stator side, $\mathrm{L}_{\mathrm{Ls}}$ and $\mathrm{L}_{\mathrm{Lr}}$ are the stator and rotor leakage inductance. $\mathrm{L}_{\mathrm{m}}$ is the magnetizing inductance, $\omega$ is synchronous speed in $\mathrm{Rad} / \mathrm{Sec}$.

The mechanical model of an induction motor is composed of the equations of motion and the driven load of the motor. This is presented in equation (16).

$$
\mathrm{T}_{\mathrm{em}}=\mathrm{T}_{\mathrm{L}}+\frac{2 \mathrm{~J}}{\mathrm{P}} \frac{\mathrm{d} \omega_{\mathrm{r}}}{\mathrm{dt}}
$$

Where: $\mathrm{P}$ is the number of pole pairs, $\mathrm{J}$ is the moment of inertia, $\omega_{\mathrm{r}}$ is the rotor electrical speed, $\mathrm{T}_{\mathrm{L}}$ is the Load torque and $\mathrm{T}_{\mathrm{em}}$ is the electromechanical torque. The machine parameters used for the simulation is presented in Table 1.

Table 1. Simulation Parameters.

\begin{tabular}{|l|c|}
\hline MACHINE PARAMETERS & VALUES \\
\hline Rated Power & 5H.P $=3730 \mathrm{~W}$ \\
\hline Rated Input Voltage & $400 \mathrm{~V}$ \\
\hline Stator Resistance & $2.2 \Omega$ \\
\hline Rotor Resistance & $0.87 \Omega$ \\
\hline Stator Leakage Inductance $\mathrm{L}_{\mathrm{Ls}}^{\prime}$ & $0.0052 \mathrm{H}$ \\
\hline Rotor Leakage Inductance $\mathrm{L}_{\mathrm{Lr}}$ & $0.0052 \mathrm{H}$ \\
\hline Magnetizing Inductance & $0.0955 \mathrm{H}$ \\
\hline Number of Pole & 4 \\
\hline Frequency (Hertz) & 50 \\
\hline Motor Speed (RPM) & 1440 \\
\hline Coefficient of Viscosity (Nms) & 0.0008 \\
\hline Motor Inertia (Kg-M $\left.{ }^{2}\right)$ & 0.07 \\
\hline Load Torque (Motoring) & $0,-20$ and -10 \\
\hline Load Torque (Generating) & 0,20 and 10 \\
\hline
\end{tabular}

\section{DC CAPACITOR VOLTAGE BALANCING IN DIODE CLAMPED CONVERTER.}

Several multi-level inverter configurations with a d.c capacitor voltage balance and pulse-width modulation (PWM) techniques have been reported in [15-21]. This section shows a simple buck-boost chopper circuits that are connected to the input d.c capacitors of a single phase midpoint five-level diode clamped converter. The buck-boost chopper circuit ensures that the d.c capacitor voltage is always balanced through the energy exchange in the inductor and the source capacitors. $S_{c a 1}$ and $S_{c a 2}$ are the chopper bidirectional switches. Each switch is made up of a unidirectional transistor switch and an anti-parallel diode.
The chopper current limiting inductors are represented by $\mathrm{L}_{1}$ and $\mathrm{L}_{2}$ while the source capacitors are represented by $\mathrm{C}_{\mathrm{d} 1}, \mathrm{C}_{\mathrm{d} 2}, \mathrm{C}_{\mathrm{d} 3}$ and $\mathrm{C}_{\mathrm{d} 4}$. The inductor $\mathrm{L}_{1}$ is applied to transfer excess capacitor stored energy between capacitors $\mathrm{C}_{\mathrm{d} 1}$ and $\mathrm{C}_{\mathrm{d} 2}$ in the upper part of the circuit. Similarly, $\mathrm{L}_{2}$ is applied to exchange capacitor stored energy between capacitors $C_{d 3}$ and $\mathrm{C}_{\mathrm{d} 4}$ in the lower part of the circuit as presented in Figure 3 .

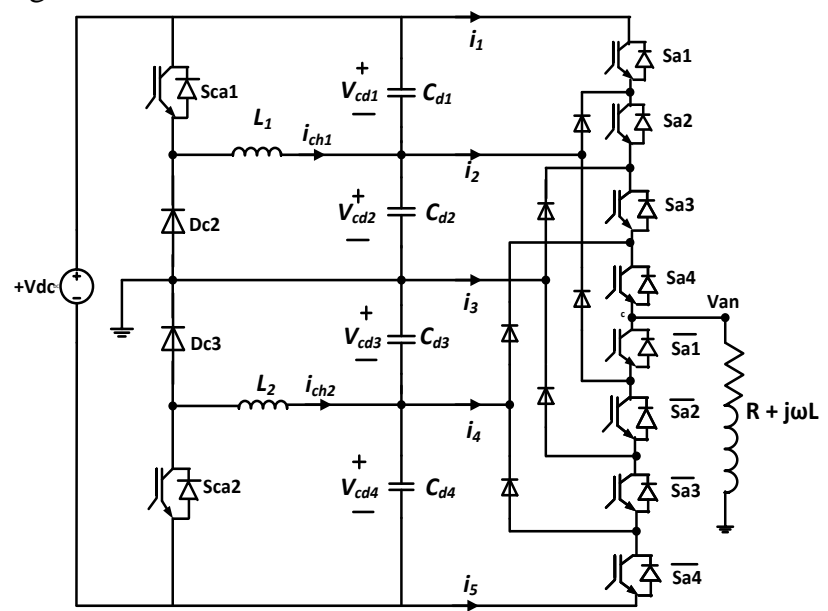

Figure 3. A Five-Level Diode Clamped Converter with an interconnected Buck-Boost Chopper Circuit.

\subsection{Control Scheme of the Five-Level Capacitor Voltage Diode Clamped Converter.}

Two stages are considered in this section. The first stage is focused on keeping the output voltage constant using a reference voltage tracking of $V_{c d r}=\frac{V_{d c}}{4}$ while the second stage involves the generation of the switching signals for $\mathrm{Sa} 1 \mathrm{Sa} 2 \mathrm{Sa} 3$ and Sa4. The complementary switching is obtained by inverting the respective signals.

First Stage: If $\mathrm{V}_{\mathrm{cd} 1} \geq \mathrm{V}_{\mathrm{cdr}}+\Delta \mathrm{V}$ and $\Delta \mathrm{V}=\mathrm{V}_{\mathrm{cd} 1}-\mathrm{V}_{\mathrm{cd} 2}$, $S_{c a 1}$ is turned on. The overcharged energy on capacitor $\mathrm{C}_{\mathrm{d} 1}$ is transferred to the inductor $\mathrm{L}_{1}$ by the flow of chopper current $i_{c h 1}$ through the loop $\mathrm{V}_{\mathrm{cd} 1} \rightarrow S_{c a 1} \rightarrow L_{1} \rightarrow \mathrm{V}_{\mathrm{cd} 1}$. When $\mathrm{C}_{\mathrm{d} 1}$ is discharged to an acceptable level of $\mathrm{V}_{\mathrm{cdr}}-$ $\Delta \mathrm{V}<V_{c d 1}<\mathrm{V}_{c d r}+\Delta \mathrm{V}, \quad S_{c a 1}$ is turned off and $S_{c a 2}$ is simultaneously turned on to charge $\mathrm{C}_{\mathrm{d} 2}$ to a level of $\mathrm{V}_{\mathrm{cdr}}-$ $\Delta \mathrm{V}<V_{c d 2}<\mathrm{V}_{c d r}+\Delta \mathrm{V}$ by transferring the energy built up in the inductor $L_{1}$ to charge $C_{d 2}$. Similarly, when $C_{d 2}$ is 
discharged to an acceptable level of $\mathrm{V}_{c d r}-\Delta \mathrm{V}<V_{c d 2}<$ $\mathrm{V}_{c d r}+\Delta \mathrm{V}, S_{c a 2}$ is turned off while $S_{c a 1}$ is turned on to charge $\mathrm{C}_{\mathrm{d} 1}$ by transferring the energy built up in the inductor $L_{1}$ to charge $C_{d 1}$. The same process applies to the energy exchange between capacitors $\mathrm{C}_{\mathrm{d} 3}$ and $\mathrm{C}_{\mathrm{d} 4}$ respectively.

Second Stage: Switching signals for $\mathrm{Sa} 1 \mathrm{Sa} 2 \mathrm{Sa} 3$ and $\mathrm{Sa} 4$ are generated using the phase-disposition sinusoidal pulsewidth modulation technique. The signals are achieved by comparing four carrier waves with a reference (modulating) wave. The four carrier waves are obtained with the aid of equations (17)-(20) having different offset values.

$$
\begin{aligned}
\operatorname{tr}_{1} & =\left[\begin{array}{ccc}
0 & \frac{1}{2 \mathrm{~F}_{\mathrm{c}}} & \frac{1}{\mathrm{~F}_{\mathrm{c}}} \\
2 \mathrm{x}-1 & 2 \mathrm{x} & 2 \mathrm{x}-1
\end{array}\right] \\
\operatorname{tr}_{2} & =\left[\begin{array}{ccc}
0 & \frac{1}{2 \mathrm{~F}_{\mathrm{c}}} & \frac{1}{\mathrm{~F}_{\mathrm{c}}} \\
\mathrm{x}-1 & \mathrm{x} & \mathrm{x}-1
\end{array}\right] \\
\operatorname{tr}_{3} & =\left[\begin{array}{ccc}
0 & \frac{1}{2 \mathrm{~F}_{\mathrm{c}}} & \frac{1}{\mathrm{~F}_{\mathrm{c}}} \\
-(\mathrm{x}-1) & -\mathrm{x} & -(\mathrm{x}-1)
\end{array}\right] \\
\operatorname{tr}_{4} & =\left[\begin{array}{ccc}
0 & \frac{1}{2 \mathrm{~F}_{\mathrm{c}}} & \frac{1}{\mathrm{~F}_{\mathrm{c}}} \\
-(2 \mathrm{x}-1) & -2 \mathrm{x} & -(2 \mathrm{x}-1)
\end{array}\right]
\end{aligned}
$$

$\operatorname{tr}_{1}-\operatorname{tr}_{4}$ represent the carrier waves. $X$ represents the amplitude of the carrier wave. At every condition $\mathrm{X} \geq 1$, $\mathrm{F}_{\mathrm{c}}$ represents the switching frequency of the carrier,

The reference (modulating) wave is derived from (21).

$$
\mathrm{V}_{\mathrm{ra}}=\mathrm{A}_{\mathrm{m}} \sin (\theta)
$$

Where: $A_{m}$ represents the amplitude of the modulating wave.

The algorithm for the switches on phase A inverter leg is presented as follows:

If $\left(V_{r a}>t r_{1}\right)$

$$
\begin{aligned}
& s_{a 1}=1 ; s_{a 2}=1 ; s_{a 3}=1 ; s_{a 4}=1 ; \\
& s_{a 1}=0 ; s_{a 2}=0 ; \frac{s_{a 3}}{s_{a 4}}=0 ; s_{a 4}=0
\end{aligned}
$$

Else if $\left(\mathrm{V}_{\mathrm{ra}}<\operatorname{tr}_{1}\right.$ and $\left.\mathrm{V}_{\mathrm{ra}}>\operatorname{tr}_{2}\right)$

$$
\begin{aligned}
& s_{a 1}=0 ; s_{a 2}=1 ; s_{a 3}=1 ; s_{a 4}=1 ; \\
& \overline{s_{a 1}}=1 ; \overline{s_{a 2}}=0 ; \overline{s_{a 3}}=0 ; \overline{s_{a 4}}=0 ;
\end{aligned}
$$

Else if $\left(\mathrm{V}_{\mathrm{ra}}<\mathrm{tr}_{2}\right.$ and $\left.\mathrm{V}_{\mathrm{ra}}>\operatorname{tr}_{3}\right)$

$$
\begin{aligned}
& s_{a 1}=0 ; s_{a 2}=0 ; s_{a 3}=1 ; s_{a 4}=1 ; \\
& \overline{s_{a 1}}=1 ; \overline{s_{a 2}}=1 ; \overline{s_{a 3}}=0 ; \overline{s_{a 4}}=0 ;
\end{aligned}
$$

Else if $\left(\mathrm{V}_{\mathrm{ra}}<\mathrm{tr}_{3}\right.$ and $\left.\mathrm{V}_{\mathrm{ra}}>\mathrm{tr}_{4}\right)$

$$
\begin{aligned}
& s_{a 1}=0 ; s_{a 2}=0 ; s_{a 3}=0 ; s_{a 4}=1 ; \\
& s_{a 1}=1 ; \overline{s_{a 2}}=1 ; \bar{s}_{a 3}=1 ; \overline{s_{a 4}}=0 ;
\end{aligned}
$$

Else $\left(\mathrm{V}_{\mathrm{ra}}<\mathrm{tr}_{4}\right)$

End

$$
\begin{aligned}
& s_{a 1}=0 ; s_{a 2}=0 ; s_{a 3}=0 ; s_{a 4}=0 ; \\
& s_{a 1}=1 ; \frac{s_{a 2}}{s_{a 3}}=1 ; s_{a 4}=1 ;
\end{aligned}
$$

\section{SIMULATION RESULTS AND DISCUSSION.}

The simulation result for the five-level diode clamped converter (DCC) with a disconnected chopper circuit is presented in Figure 4. It is evidently shown that in the absence of the chopper circuit (disconnected buck-boost chopper circuit), an unbalanced state of the capacitor voltage is obtained. This is observed in the rising with time of the unbalanced state of the dc capacitor voltage waveforms shown in Figure 4 where the capacitor voltages
$\mathrm{V}_{\mathrm{cd} 1}$ and $\mathrm{V}_{\mathrm{cd} 4}$ increased progressively from $\frac{V_{d c}}{4}$ at the same rate that $\mathrm{V}_{\mathrm{cd} 2}$ and $\mathrm{V}_{\mathrm{cd} 3}$ decreased from $\frac{V_{d c}}{4}$. The increase and decrease in the capacitor voltage is as a result of the flow of unequal branch currents $i_{1}$ to $i_{5}$ of Figure 3 . This therefore implies that under steady state operation, only $\mathrm{C}_{\mathrm{d} 1}$ and $\mathrm{C}_{\mathrm{d} 4}$ need to be discharged from their excess voltages to $V_{c d r}=$ $\frac{V_{d c}}{4}$. The excess energy recovered from the chopper inductors is then applied to charge up $\mathrm{C}_{\mathrm{d} 2}$ and $\mathrm{C}_{\mathrm{d} 3}$ to $V_{c d r}=$ $\frac{V_{d c}}{4}$. Figure 5 represents the output voltage waveform for the balanced capacitor voltage and five-level inverter output phase voltage under steady state condition. In Figure 5 , it is observed that each of the four capacitor voltages closely track the reference voltage $V_{c d r}=\frac{V_{d c}}{4}=100 \mathrm{~V}$. This gives a high quality inverter output voltage under a prolonged steady state condition as against Figure 4 waveform. The simulation results for the squirrel cage induction motor showed that there is an overshoot in the speed of the machine during starting as shown in Figures 8 and 15. At start, the machine speed rises to $164.8 \mathrm{Rad} / \mathrm{Sec}$ at 0.053 second in motoring condition whereas the rise in speed in generating condition is $331.4 \mathrm{Rad} / \mathrm{Sec}$. which is equivalent to twice the value obtained in motoring state on no-load. When a periodic load as shown in Figure 6, is applied on the machine at a varied time interval of $[0.5$, $1.0 ; 1.5 ; 2.0]$ second the motor speed drops in the sequence of $[156.7 ; 155.5 ; 156.1 ; 159.1] \mathrm{Rad} / \mathrm{Sec}$. as presented in Figure 8 for motoring condition and $[315.5 ; 312.7 ; 313.4$; 312.7] $\mathrm{Rad} / \mathrm{Sec}$. for generating condition as shown in Figure 15. Similarly, the electromechanical torque in motoring condition changes in line with the speed in the sequence $[73.72 ; 49.96 ; 25.92 ;-24.94] \mathrm{Nm}$ and $[-19.59$; 19.87; 9.693; 19.6] $\mathrm{Nm}$ for generating condition. The simulation result presented in Figure 9 also showed that during start-up, the machine on no-load and on periodic loading operation draws much current and produces oscillatory torques which is presented in Figure 7 and in Figure 14.
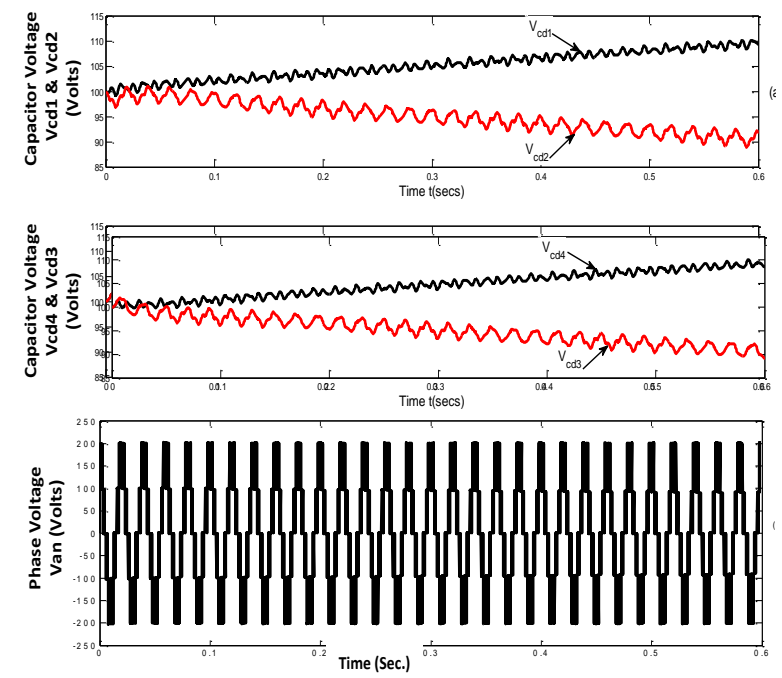

Figure 4. Five Level DCC waveforms with a disconnected chopper circuit. $\mathrm{C}_{\mathrm{d} 1} \& \mathrm{C}_{\mathrm{d} 2}=\mathrm{C}_{\mathrm{d} 3} \& \mathrm{C}_{\mathrm{d} 4}=2000 \mu \mathrm{F}, \mathrm{V}_{\mathrm{dc}}=400 \mathrm{~V}, \mathrm{~F}_{\mathrm{c}}=1.05 \mathrm{KHz}, \mathrm{F}_{\mathrm{s}}=$ $50 \mathrm{~Hz}, \mathrm{M}=0.8, \mathrm{Z}_{\mathrm{L}}=(8+6 \mathrm{j}) \Omega$. 

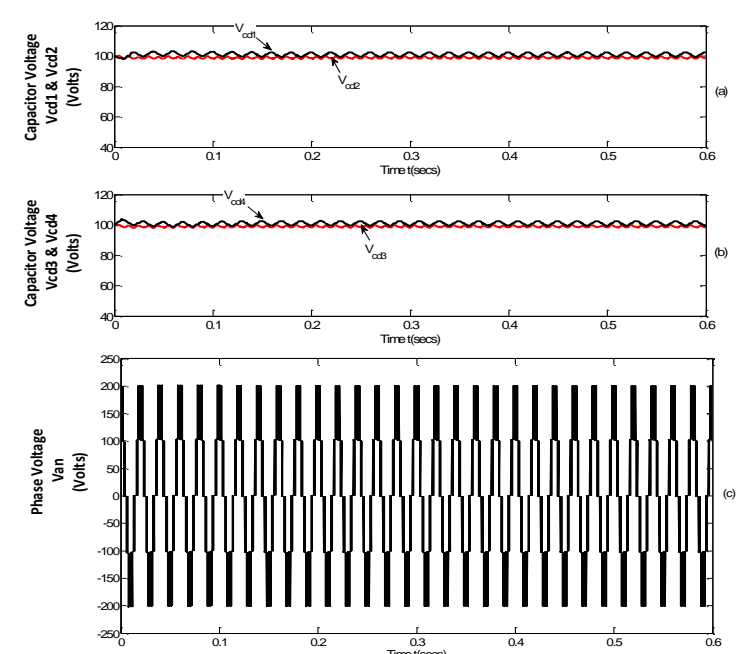

Figure 5. Five Level DCC waveforms with an interconnected chopper circuit. $\mathrm{C}_{\mathrm{d} 1} \& \mathrm{C}_{\mathrm{d} 2}=\mathrm{C}_{\mathrm{d} 3} \& \mathrm{C}_{\mathrm{d} 4}=2000 \mu \mathrm{F}, \mathrm{V}_{\mathrm{dc}}=400 \mathrm{~V}, \mathrm{~F}_{\mathrm{c}}=1.05 \mathrm{KHz}, \mathrm{F}_{\mathrm{s}}=$ $50 \mathrm{~Hz}, \mathrm{M}=0.8, \mathrm{Z}_{\mathrm{L}}=(8+6 \mathrm{j}) \Omega$.

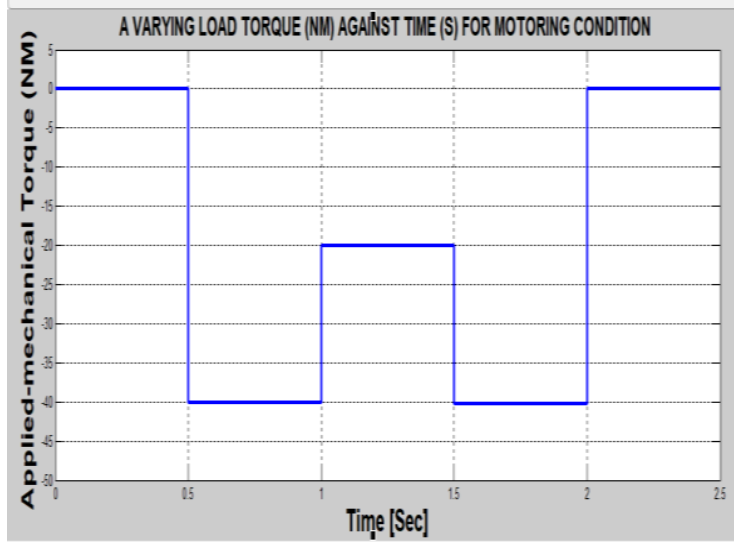

Figure 6. A Plot of Applied-Mechanical Load Torque (NM) against Time (Sec.) (Motoring State)

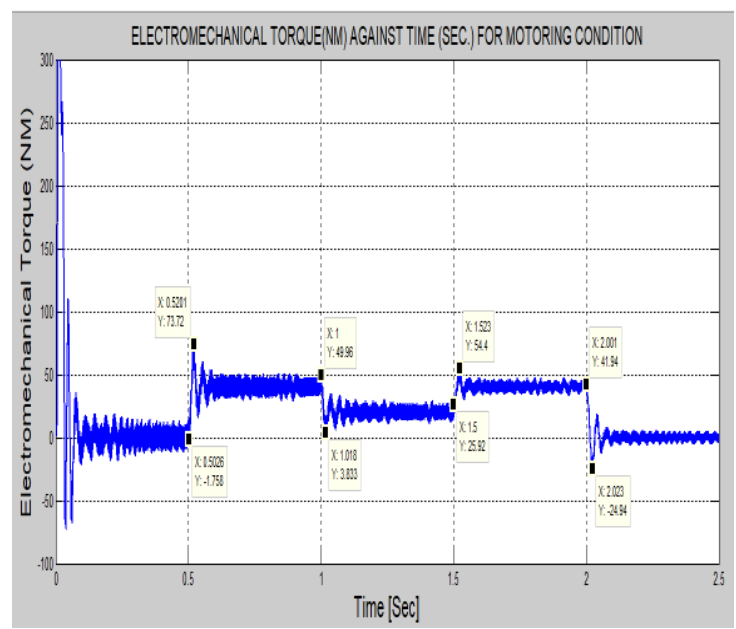

Figure 7. A Plot of Electromechanical Torque against Time (Motoring State).

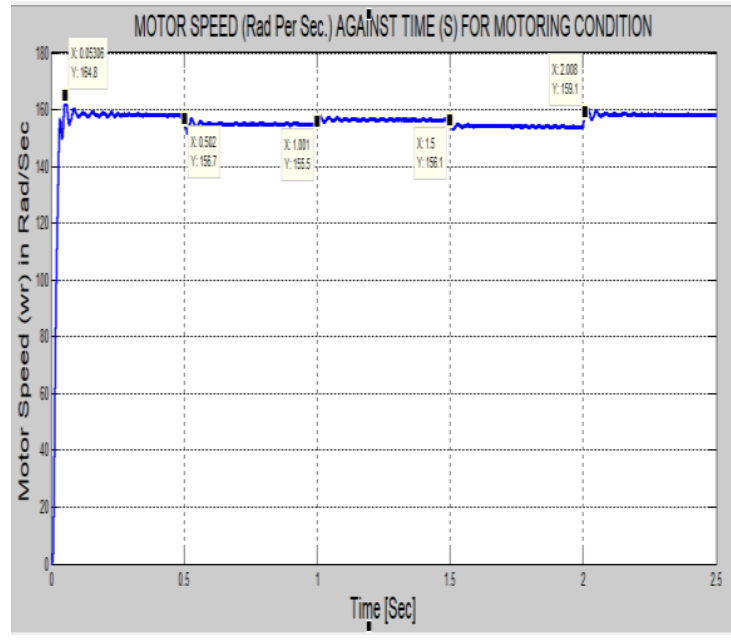

Figure 8. A Plot of Motor Speed against Time (Motoring State)
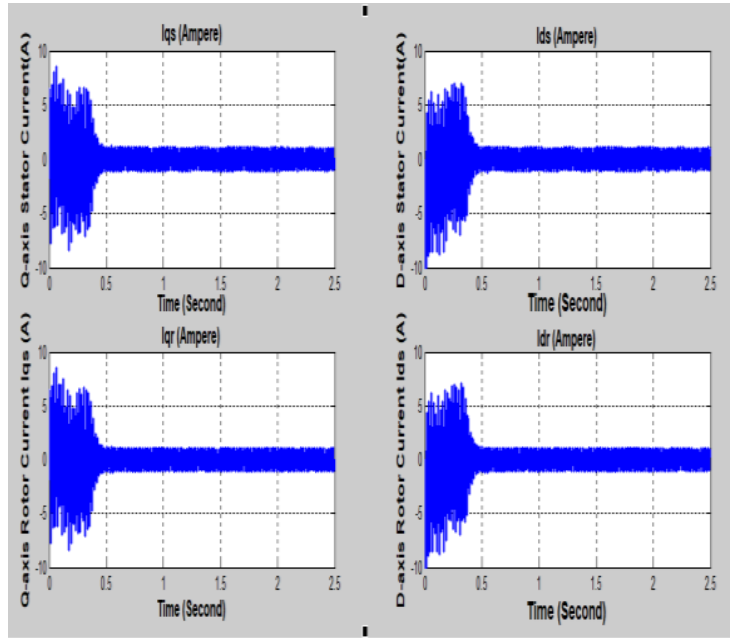

Figure 9. A Plot of Stator and Rotor qd-axes currents (A) against Time (Sec.).

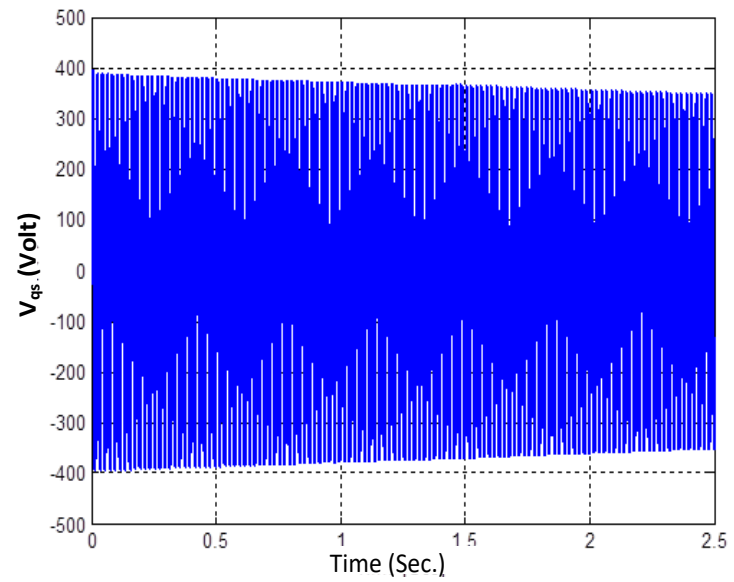

Figure 10. A Plot of Q-axis phase voltage (A) against Time (Sec.). 


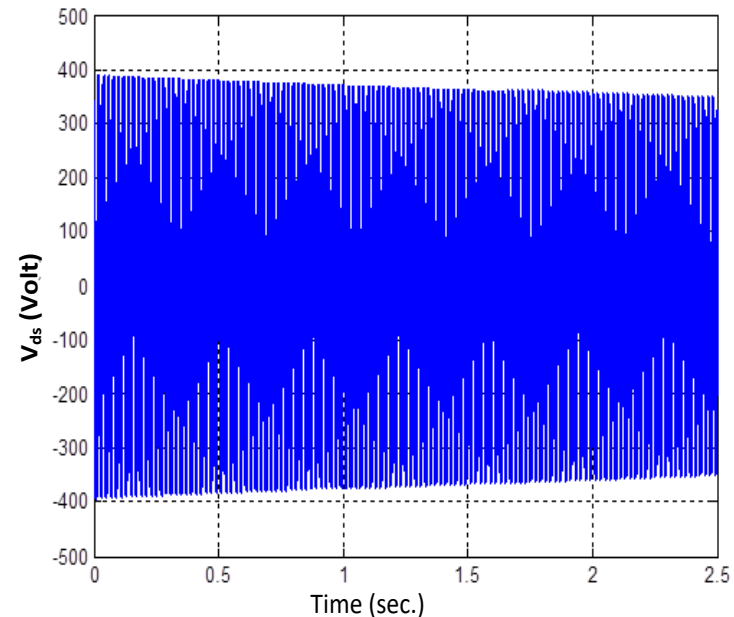

Figure 11. A Plot of D-axis phase voltage (V) against Time (Sec).

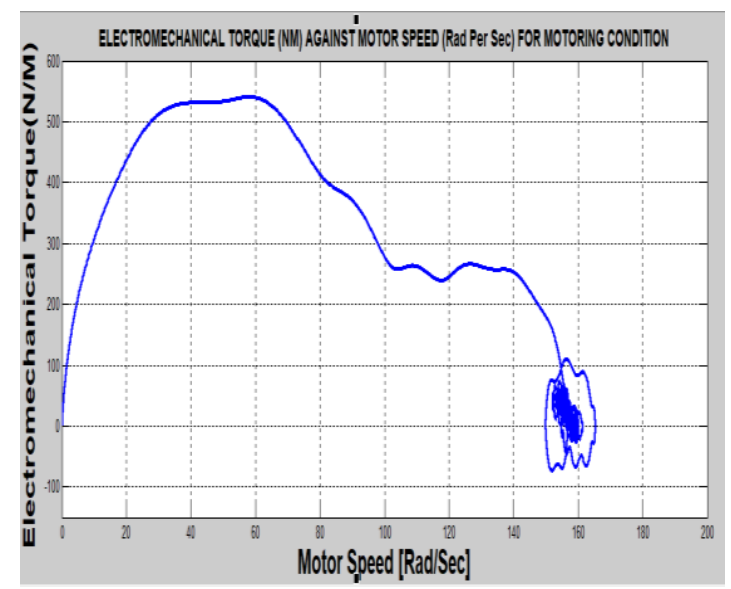

Figure 12. A Plot of Electromechanical Torque against Speed (Motoring State).

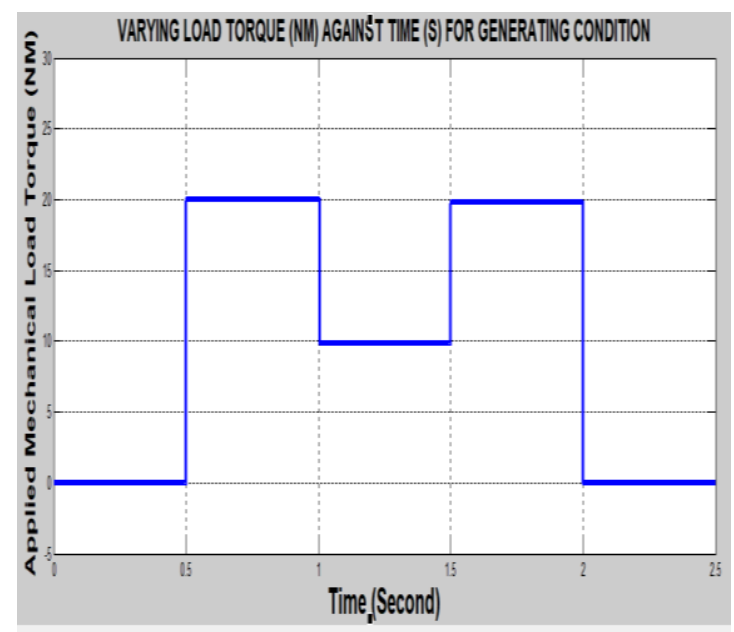

Figure 13. A Plot of Applied-Mechanical Load Torque against Time (Generating State).

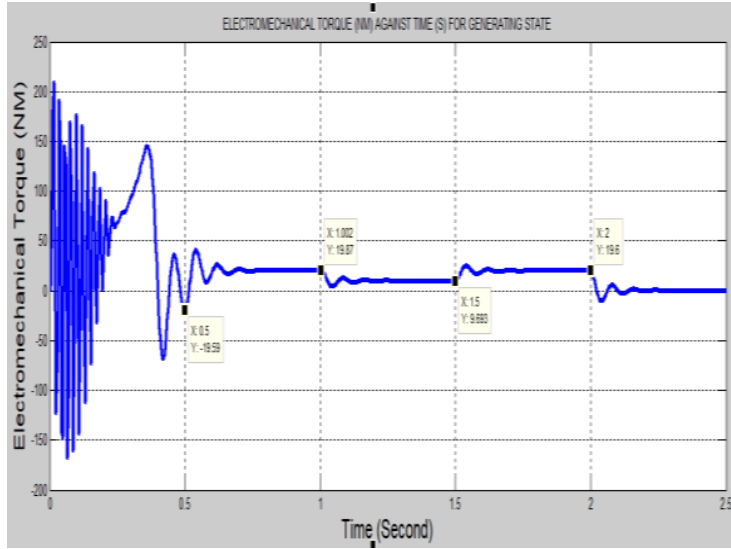

Figure 14. A Plot of Electromechanical Torque against Time (Generating State).

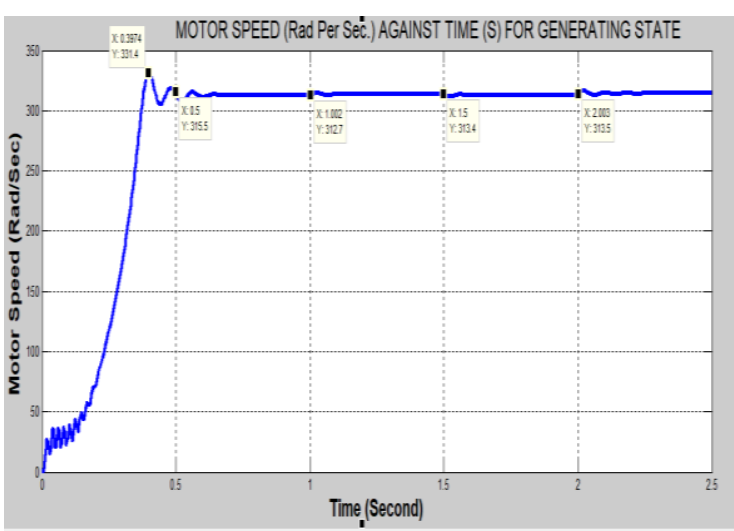

Figure 15. A Plot of Motor Speed against Time (Generating State)

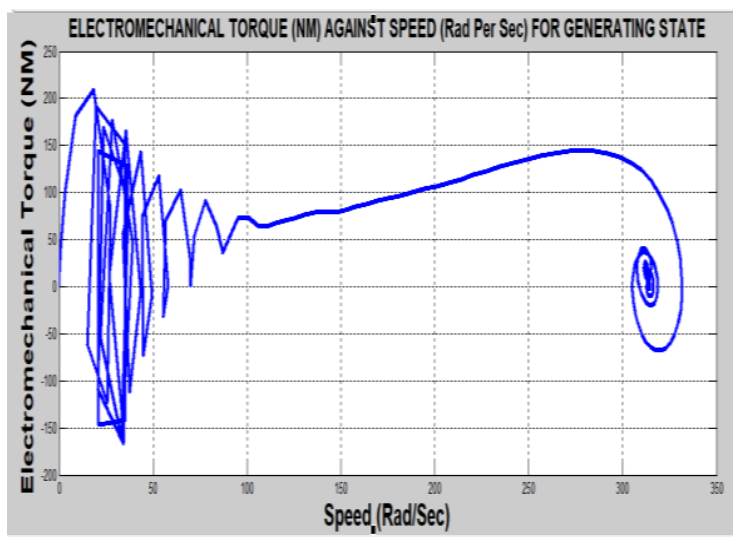

Figure 16. A Plot of Electromechanical Torque against Speed (Generating State).

\section{CONCLUSION}

The concept of speed control with a low frequency stator boost voltage was analyzed with respect to variable voltage and frequency ratio. A well balanced capacitor voltage fed five-level diode clamped converter (DCC) was modeled to drive a $5 \mathrm{Hp}$ squirrel cage induction motor in motoring and in generating mode of operations. The simulation results obtained and presented in Figures 4 and 5 indicate that an unsymmetrical voltage distribution across the inverter leg is achieved with an unbalanced capacitor voltage. Conversely, a symmetrical and high quality voltage distribution is achieved across the inverter leg for a wellbalanced capacitor voltage. This work has shown that there 
is an appreciable rise in the speed of the squirrel cage induction motor during a generating condition over the motoring condition. The results equally proved that a periodic loading of the machine always lead to sudden changes in speed with a resultant rise and fall in the electromechanical torque.

\section{REFERENCES}

[1] Krause, P.C. Wasycnczuk, O. and Sudhoff, S.D. Analysis of electric Machinery and Drive Systems. IEEE Press Power Engineering Series, $2^{\text {nd }}$ edition, 2002.

[2] Okoro, O.I. "Steady State and Transient Analysis of Induction Motor Driving a Pump Load," Nigerian Journal of Technology (NIJOTECH), Vol. 22, No.1 pp.46-53, March 2003.

[3] Richard, M.C. Electric Drives and Their Control. Oxford University Press New York $4^{\text {th }}$ edition 2012.

[4] Mora, J.F. Electrical Machines, McGraw Hill New York, 2003.

[5] Kumar, M. Babu, P. and Ramprasath, S. "Four Quadrant Operation of Direct Torque Control SVPWM Based Three Phase Induction Motor Drive in MATLAB/SIMULINK Environment," Proceedings of the IEEE International Conference on Advanced Communication Control and Computing Technologies (ICACCCT), pp.397-402, 2012.

[6] Ogbuka, C.U. "A Modified Approach to Induction Motor Stator Voltage and Frequency Control," Proceedings of the World Congress on Engineering Vol. 11, July 6-8, London, 2011.

[7] Alfredo, M.G. Lipo, T. and Novotry, D.W. "A New Induction Motor V/F Control Method capable of High Performance Regulation at low Speed," IEEE Trans. Industrial Application, Vol. 34, No. 4, pp.813-820, 1998.

[8] Dubey, G.K. Fundamentals of Electric Drives. Narosa Publishing House, $2^{\text {nd }}$ edition New Delhi, 2011

[9] Bimbhra, P.S. Electrical Machinery $7^{\text {th }}$ edition, Khamma Publishers, New Delhi, 2010.

[10] Kashappa, N. and Ramesh, R.K. "Performance of Voltage Source Multi-level Inverter Fed Induction Motor Drive Using SIMULINK," ARPN Journal of Engineering and Applied Sciences, Vol.6, No.6, June, 2011.

[11] Wade, S. Dunnigan, M.W. and Williams, B.W. "Modelling and Simulation of Induction Machine Vector Control with Rotor Resistance Identification," IEEE Transaction on Power Electronics, Vol. 12, No.3, May, 1997.
[12] Ogbuka, C.U. and Agu, M.U. "Effects of Load and Speed Variations in a Modified Closed Loop V/F Induction Moto Drive," Nigerian Journal of Technology (NIJOTECH), Vol. 31,No.3, pp.365- 369, 2012.

[13] Oti, S.E. Nwosu, C.M. Nnadi, D.B. and Okoro, O.I. "Performance Study of Three-phase Induction Motor driving a Load," Discovery Journal, Vol. 55, pp.279-290, 2019.

[14] Okoro, O.I. "Computer Simulation of Induction Machine Coupled to a Mechanical Load," Nigerian Journal of Engineering Management, (NJEM) Vol.4, No. 4, pp.28-38, 2003.

[15] Marchesoni, A. and Tenca, P. "Diode Clamped Multi-level Converters: A Practical Way to Balance DC-Link Voltages,' IEEE Trans. Industrial Electronics, Vol. 49, No.4, pp. 752-765, August, 2002

[16] Zhiguo, P. Peng, F.Z. Corzino, K.A. Stefanovic, Balancing Control of Diode Clamped Rectifier/Inverter Systems," IEEE Trans. Industrial Application, Vol. 41, No.6, pp.1698-1706, Nov./Dec. 2005

[17] Liu, Y. and Luo, F.I. "Multi-level Inverter with the Ability of Self Voltage Balancing," In IEE Proc. Electric Power Application Vol. 153, No.1, pp.105-115, January, 2006.

[18] Perez, M. Bernet, S. Rodriguez, J. Kouro, S. and Lizana, R. "Circuit Topologies, Modelling Control Schemes and Applications of Modular Multi-level Converters," IEEE Trans Power Electronics Vol.30, No.1, pp.4-17, January, 2015.

[19] Deng, F. and Chen, Z. "A Control Method for Voltage Balancing in Modular Multi-level Converters," IEEE Trans. Power Electron, Vol. 21, No.1, pp. 66-76, January 2014

[20] Yu, F. Lin, W. Wang, X. and Xie, D. "Fast Voltage Balancing Control and Fast Numerical Simulation Model for the Modula Multi-level Converter," IEEE Trans, Power Delivery, Vol. 30, No.1, pp. 220-228

[21] Siemszko, D. "Fast Sorting Method for Balancing Capacitor Voltages in Modular Multi-level Converters," IEEE Trans. Power Electron., Vol. 30, No.1, pp.463-470, January, 2015. 